\title{
PLANTÃo PSICOLÓGICO, UNIVERSIDADE PÚBLICA E POLÍTICA DE SAÚDE MENTAL
}

\author{
PSYCHOLOGICAL EMERGENCY ATTENDANCE, PUBLIC \\ UNIVERSITY AND THE MENTAL HEALTH POLICY
}

Maria Luisa Sandoval SCHMIDT ${ }^{1}$

\begin{abstract}
RESUMO
Este artigo analisa a prática de Plantão Psicológico no contexto da crise universitária e do desmanche dos serviços públicos de saúde mental na cidade de São Paulo. Define a prática de Plantão Psicológico e explicita o panorama empírico no qual se encontra a partir da implementação das reformas neoliberais das políticas públicas na área da saúde. Apresenta e discute a "modernização" da universidade pública e suas implicações na esfera da prestação de serviços universitária. Finalmente, esboça algumas propostas de enfrentamento da situação de crise dos serviços universitários e, mais especificamente, o Plantão Psicológico.
\end{abstract}

Palavras-chave: plantão psicológico; serviços de extensão universitária; políticas públicas de saúde; reforma de estado.

\begin{abstract}
This study analyzes the Psychological Practice in the context of university's crises and the dismount of public mental health services in São Paulo. It defines the Psychological Emergency Practice and put in evidence the actual empiric panorama due to the health public policy neo-liberal innovations. It presents and discusses the public university modernization and its influence on the university services. Finally, it outlines some university services' proposes to face up the crises' situation, specially the Psychological Emergency Practice.
\end{abstract}

Key-words: psychological emergency attendance; university services; health public policies; state government reform program.

\footnotetext{
${ }^{1}$ Departamento de Psicologia da Aprendizagem, do Desenvolvimento e da Personalidade, Instituto de Psicologia, Universidade de São Paulo. Rua Prof. Mello Moraes, 1721, Cidade Universitária, 05508-900, São Paulo, SP, Brasil.
} 
O Plantão Psicológico vem sendo teorizado e praticado no Instituto de Psicologia da Universidade de São Paulo como modo privilegiado de responder à pluralidade e à diversidade de demandas por ajuda psicológica advindas da clientela e como contexto para a formação de psicólogos comprometidos com a saúde pública.

A crise dos modelos de prestação de serviços, em sua relação com a pesquisa e o ensino, no âmbito universitário, e a maneira como as políticas sociais, mais especificamente as de saúde, vêm sendo concebidas e conduzidas pelo projeto de um governo neoliberal colocam questões cruciais à prática do Plantão Psicológico e impõem a tarefa de pensar formas de enfrentar e resistir à atual conjuntura das políticas de saúde mental. A universidade pública, neste caso a Universidade de São Paulo (USP), apresenta-se como lugar possível de resistência e de produção de um pensamento crítico em relação às propostas e ações autoritárias do projeto neoliberal, mas, concomitantemente, é, ela mesma, alvo destas proposições e ações que, em vastos setores de suas atividades acadêmicas e de gestão administrativa, tornaram-se hegemônicas. Os impasses enfrentados na condução do Plantão Psicológico vêm se agudizando e exibem-se na confluência dos efeitos das políticas adotadas para a saúde e para a educação no âmbito federal, estadual e municipal, nas quais um item visível e contundente tem sido o desmantelamento, através de vários dispositivos, dos serviços públicos e dos efeitos do projeto de "modernização" da universidade pública. A crise, por assim dizer, do Plantão Psicológico é, portanto, uma das expressões das crises por que passam os serviços de saúde e as universidades públicas.

Encarar essa conjuntura adversa de modo conseqüente, no plano ético e político, requer um trabalho de pensamento que, por um lado, esclareça, na medida do possível, os termos destas chamadas "crises" e, por outro, aponte propostas de resistência e enfrentamento cuja efetividade depende de um esclarecimento e de um engajamento coletivos.
Este trabalho busca compreender a "microcrise" do Plantão Psicológico através da investigação de suas relações com as políticas de saúde metal e de sua inserção numa universidade pública, seguindo os seguintes passos: a) definição da prática de Plantão Psicológico e explicitação do panorama no qual se encontra a partir do desmanche de grande parte dos recursos de saúde mental na cidade de São Paulo; b) apresentação e discussão das propostas de "modernização" da universidade segundo o modelo neoliberal, através de autores que têm se dedicado ao tema; c) análise da situação da Universidade de São Paulo em relação às mudanças nas concepções das atividades de extensão em suas conexões com o ensino e a pesquisa; d) indagação em torno de propostas de ações na atual situação.

\section{O Plantão Psicológico e as políticas de saúde mental}

O Plantão Psicológico é pensado e praticado, basicamente, como um modo de acolher e responder a demandas por ajuda psicológica. Isso significa colocar à disposição da clientela que o procura um tempo e um espaço de escuta abertos à diversidade e à pluralidade dessas demandas.

É necessário, contudo, clarificar os significados que acolher e responder assumem no Plantão Psicológico. Acolher refere-se, nesse caso, a uma peculiar atenção para a experiência do cliente no momento em que procura ajuda, que inclui não apenas o que convencionalmente se entende por queixa, mas o modo como o cliente vive essa queixa, os recursos subjetivos e do entorno sociopsicológico de que dispõe para cuidar de seu sofrimento, bem como as expectativas e perspectivas que se apresentam a partir da busca de auxílio.

Responder, por sua vez, associa-se à explicitação da demanda e seus possíveis desdobramentos de tal forma que, ao acolher o cliente, está-se, ao mesmo tempo, dando-Ihe a oportunidade de se posicionar frente àquilo que 
vive e permitindo ao serviço um posicionamento em relação àquilo que pode ou não oferecer, no sentido de dar continuidade a um primeiro contato. Responder é central para a especificidade do Plantão Psicológico. Diferentemente da triagem que, grosso modo, visa avaliar a adequação entre o serviço que se presta e a demanda do cliente, no Plantão Psicológico trata-se, sempre, de responder à demanda, embora haja momentos e ocasiões em que ela não possa ser atendida no âmbito do Serviço de Aconselhamento Psicológico (SAP).

Por acolher a diversidade de demandas que se apresentam, sem nenhuma previsibilidade, a cada período, o Plantão Psicológico requer sensibilidade e invenção nos modos de responder, que também se caracterizam pela diversidade, singularidade e pluralidade ${ }^{2}$.

Embora o Plantão Psicológico tenha, a priori, alguns desdobramentos previstos em sua rotina - tais como início de uma psicoterapia, retornos, encaminhamentos -, há sempre o imperativo de cotejar aquilo que o cliente compreende como sendo a sua necessidade no momento e aquilo que o serviço em questão pode, adequadamente, oferecer. A ponderação sobre este aspecto fundamental - responder à diversidade de demandas, sem, contudo, poder atendê-las todas - faz pensar no quanto um serviço de Plantão Psicológico não pode e não deve se tomar como auto-suficiente. Na contrapartida, faz pensar no quanto um serviço deste tipo só pode ser concebido numa relação de solidariedade com os recursos pessoais da clientela, com os recursos coletivos das comunidades e, finalmente, com os recursos institucionais das esferas pública e privada disponíveis na sociedade.

Propor-se a responder à diversidade e às singularidades das demandas por ajuda psicológica que se constelam na prática de plantão só é possível quando essa prática estabelece os laços de solidariedade, as alianças, as trocas que permitem contar com o apoio de âmbitos mais amplos do que aqueles que um serviço universitário pode abranger.

Desde o início dos anos 90, o Plantão Psicológico do Instituto de Psicologia da Universidade de São Paulo (IPUSP) ${ }^{3}$ experimenta um aumento cada vez mais expressivo do número de clientes, paralelamente a um agravamento dos problemas emocionais da clientela. Esta tendência torna-se mais evidente e contundente a partir de 1995. Esta afluência de clientes, boa parte deles com experiências emocionais e condições de vida que requerem cuidados intensos, coincide com a progressiva degradação da situação socioeconômica da população de média e baixa renda e a concomitante desarticulação e descaracterização dos serviços públicos de saúde mental na grande São Paulo.

O desmantelamento da rede pública de atenção à saúde mental repercute no Plantão Psicológico em, pelo menos, duas frentes: por um lado, ao manter-se estruturado e aberto, acaba por receber uma parte da clientela que é expulsa do atendimento público, ou pela especificidade e gravidade de sua problemática, ou pelo simples desaparecimento do serviço ao qual anteriormente tinha acesso ${ }^{4}$; por outro lado,

\footnotetext{
2 Para um maior detalhamento da proposta de plantão psicológico sugere-se a consulta à seguinte bibliografia básica: Mahfoud (1987) e Morato (Org.) (1999).

3 O Plantão Psicológico constitui-se a porta de entrada para o Serviço de Aconselhamento Psicológico (SAP), funcionando, tradicionalmente, todas as quartas-feiras das 9 às 12 horas e das 14 às 16 horas. Em termos práticos, isto significa que todas as pessoas que procuram o serviço nestes períodos devem ser recebidas e ouvidas numa entrevista de duração variável, dependendo da necessidade dos clientes, do número de plantonistas disponíveis e do número de pessoas na sala de espera. Desta primeira entrevista derivam desdobramentos que contemplam retornos do cliente com o mesmo plantonista, processos de encaminhamento interno e externo, início de atendimentos com formas matizadas de contratos.

${ }^{4}$ Os serviços prestados pelo SAP foram regionalizados em 1993, justamente como uma tentativa de manter a qualidade do atendimento. Naquela época, o SAP passou a atender, exclusivamente, a comunidade USP (alunos, docentes, funcionários e seus familiares) e a clientela residente na zona oeste da cidade de São Paulo. No Plantão, porém, todas as pessoas que chegam são recebidas e ouvidas, buscando-se um encaminhamento adequado para aquelas que residem em outras regiões da cidade, ou mesmo em outros municípios.
} 
deixa de contar com o apoio de equipamentos de saúde mental para os quais a clientela poderia ser encaminhada com segurança.

A constituição de uma rede de equipamentos de saúde mental capaz de atender às demandas da cidade de São Paulo, na perspectiva da luta antimanicomial, foi alvo de políticas públicas estaduais e municipais num passado recente e sofre, atualmente, as conseqüências funestas de pelo menos duas gestões, tanto ao nível estadual quanto municipal, em que a saúde mental não foi priorizada e em que as propostas de privatização dos serviços de saúde avançaram: no âmbito municipal através da implantação do Plano de Atendimento à Saúde (PAS) e no estadual, através de uma progressiva redução dos recursos materiais e de pessoal destinados à saúde que degrada os serviços e prepara a privatização (Plano..., s/d.) .

O percurso, os avanços e as vicissitudes da rede pública de atendimento à saúde mental esclarecem, em parte, os caminhos e descaminhos do Plantão Psicológico, uma vez que, como já foi afirmado, esta prática depende do apoio e da solidariedade que a rede oferece (ou deixa de oferecer). Uma breve referência a este percurso faz-se, portanto, necessária.

No plano estadual, os avanços mais significativos no atendimento à saúde mental ocorreram no Governo de Franco Montoro (PMDB), que implementou várias propostas do Programa de Reorientação da Assistência Psiquiátrica Previdenciária elaborado por comissão do Conselho da Administração de Saúde Previdenciária (CONASP) do Ministério da Previdência e Assistência Social (MPAS), aprovado em dezembro de 1982. Este programa foi criado com os objetivos de melhorar a qualidade da assistência na área de saúde mental e planejar o uso de recursos, aumentando sua produtividade. Seus princípios, tal como aparecem no texto de sua regulamentação, incluíam a regionalização e hierarquização dos serviços, a priorização do atendimento primário e da capacidade instalada do setor público, responsabilidade do Estado na definição e condução das políticas, integração interinstitucional, descentralização administrativa e desburocratização dos procedimentos, estabelecimento de mecanismos de avaliação e participação dos vários agentes, incluindo usuários, no processo de prestação de serviços, entre outros (Instituto Nacional de Assistência Médica da Previdência Social, 1983, p.13).

Os princípios específicos da área de saúde mental serão também aqui referidos para que se possa comentar o modo como foram transpostos para a prática, no âmbito das instituições de saúde estaduais, na cidade de São Paulo. Esses princípios fundam-se na concepção do "distúrbio psiquiátrico" como "episódio no ciclo natural de saúde/doença do indivíduo" e abrangem: atendimento predominantemente extra-hospitalar; constituição de equipes multiprofissionais; prioridade a estratégias de atenção primária, regionalizada, através de ambulatórios e centros de saúde, com a constituição de equipes de saúde mental nesses equipamentos e supervisão e orientação de atendimentos realizados por médicos generalistas e, também, através de ações de prevenção e promoção de saúde mental; criação e utilização de recursos extra-hospitalares tais como hospital-dia, pré-internação, pensão protegida e oficinas; estabelecimento de critérios e formas de controle para a internação em hospital psiquiátrico e instalação de pequenas unidades psiquiátricas em hospitais gerais, incentivando a participação dos hospitais de ensino nessa empreitada (Instituto Nacional de Assistência Médica da Previdência Social, 1983, p.14).

Os princípios acima explicitados tomaram corpo na gestão de Franco Montoro, dando início a uma ampla reformulação do atendimento à saúde mental. Em resposta à prioridade dada às ações de atenção primária, foram criadas equipes mínimas de saúde mental para atuarem nos centros de saúde. A prática destas equipes incluía tanto o atendimento direto à população quanto a assessoria e supervisão dos serviços prestados por médicos generalistas. A presença dessas equipes nos centros de saúde teve desdobramentos na esfera da prevenção, da mudança de mentalidade sobre o sofrimento 
psíquico entre profissionais e comunidade, na construção de experiências de trabalho multiprofissional.

Ao mesmo tempo, criaram-se maneiras de dar suporte ao atendimento ambulatorial que, anteriormente, atinha-se às consultas psiquiátricas com ênfase na medicação. Fazem parte dessas iniciativas a realização de grupos psicoterapêuticos (para familiares de pacientes psiquiátricos, mães, mulheres, adolescentes), grupos de terapia ocupacional, visitas domiciliares. A idéia era ampliar as possibilidades de acolhida dos ambulatórios, aumentando a freqüência dos usuários e diversificando a natureza dos serviços oferecidos: com isso, buscava-se evitar a internação em hospital psiquiátrico. Um exemplo deste tipo de ação foi o Programa de Intensidade Máxima (PIM) que procurava acolher e tratar, no espaço ambulatorial, pacientes em crise e seus familiares. Uma relativa democratização da gestão dos serviços também foi conseguida, abrindo-se, inclusive, alguma oportunidade para a participação de usuários.

A prática dos profissionais de saúde mental experimentou, sem dúvida, mudanças significativas $^{5}$, não necessariamente extensivas e homogêneas em relação ao conjunto das unidades de saúde na cidade de São Paulo. Os centros de saúde-escola ligados à Universidade de São Paulo, tiveram um papel de ponta na busca de uma transformação das ações e das idéias relativas ao sofrimento psíquico, à chamada "doença mental" e às experiências de loucura. $A$ necessidade de integração dos recursos disponíveis na cidade, por sua vez, propiciou a aproximação e um maior conhecimento mútuo entre os diferentes equipamentos, dando origem a redes formais e informais de referências pautadas pela regionalidade e pela natureza dos serviços prestados.

Este período germinal do projeto para a área de saúde mental foi acompanhado de uma intensa mobilização dos trabalhadores de saúde mental que encontraram modos efetivos de organização, de debate de idéias e de troca de experiências.

A constituição de uma estrutura ligada ao ideário da atenção primária, do atendimento extra-hospitalar, da abordagem interdisciplinar e multiprofissional e da regionalização, em saúde mental, teve uma certa continuidade no governo de Orestes Quércia. Nos governos seguintes (Fleury e Covas), porém, observa-se um progressivo esmorecimento da vontade política de fazer valerem os princípios que nortearam a experiência iniciada no governo de Franco Motoro. No Programa de Governo - 1999-2002 (s.d.) de Mário Covas, as prioridades para a saúde são a expansão do Projeto Qualis ${ }^{6}$, saneamento básico e a criação de hospitais geridos como organização social ${ }^{7}$. A saúde metal aparece referida num único parágrafo, no qual se lê que:

Os portadores de doenças mentais terão melhorado seu atendimento através da manutenção da Política de Modernização e de Humanização do Governo Mário Covas, e pela implantação de Hospitais-Dia e

\footnotetext{
${ }^{5}$ Robert Musil, no livro Da estupidez (Lisboa: Relógio D’Água Editores, 1994), oferece uma definição do que seja significativo. Ele escreve: "O significativo associa a verdade que nós podemos perceber nele às qualidades do sentimento que têm a nossa confiança para dele extrair o completamente novo, que é ao mesmo tempo compreensão e decisão, uma obstinação retemperada, qualquer coisa que dispõe de um conteúdo ao mesmo tempo mental e psíquico e que 'exige' de nós ou dos outros um certo tipo de comportamento; poder-se-ia pois dizer, e no que diz respeito à estupidez isso é o essencial, que o significativo é acessível tanto ao aspecto racional como ao aspecto afectivo da crítica. O significativo é também, ao mesmo tempo, o contrário da estupidez e da brutalidade; e o mal-entendido geral que permite hoje aos afectos asfixiar a razão, em vez de Ihe dar asas, fica abolido na noção de significativo" (p.35).

${ }^{6}$ O Projeto Qualis pretende promover "o atendimento integral à família através da atuação de equipes de saúde, integradas por médico, enfermeiro, dentista, auxiliar de enfermagem e agentes comunitários de saúde" (Mário Covas, Programa de Governo 1999-2002, p.29).

${ }^{7}$ A idéia de transformar as instituições públicas de educação e saúde em organizações sociais faz parte do plano de reforma do Estado orquestrado por Bresser Pereira e será detalhada na discussão sobre universidade pública.
} 
Centros de Apoio Psicossocial ${ }^{8}$ e pelo apoio na formação de novas equipes multiprofissionais de saúde mental para permitir a expansão da rede ambulatorial e dos programas de tratamento tendo em vista os usuários de drogas (p.30).

Aquilo que aí se explicita como meta para a saúde mental denuncia a necessidade de criar e constituir, de modo incipiente e sem fazer menção à luta antimanicomial, alguns dos recursos que já tinham sido implantados e que foram, na verdade, desconstruídos.

No âmbito municipal, a gestão petista de Luiza Erundina (1989-1993) estabeleceu e implementou uma política de saúde mental engajada no combate à "cultura hospitalocêntrica" e na criação de uma rede de atendimento alternativa à hospitalização e psiquiatrização das demandas.

No documento Diretrizes para a política de saúde mental no Município de São Paulo (1989/Gestão Democrática e Popular), o programa de ações prioriza: a criação de conselhos populares de saúde nos serviços de saúde metal; o combate ao sistema manicomial; a humanização das relações e práticas de atendimento; o investimento na mudança de mentalidade sobre a loucura com a promoção de espaços de discussão junto à população e aos sindicatos; a valorização dos saberes e práticas populares e a conseqüente relativização dos saberes e práticas médico-psicológicos; a integração de diferentes serviços; o incentivo à formação de profissionais de saúde mental; a desativação de convênios da Prefeitura com empresas privadas de saúde mental; a fiscalização do tempo e das condições de internamento de pacientes em hospitais públicos ou privados e a criação de espaços de convivência e lares abrigados.
Em relação às ações implementadas pelo Governo do Estado, a proposta da Prefeitura avança no que diz respeito à gestão democrática dos serviços, através da criação de conselhos e na valorização dos saberes populares, e, também, no combate ao sistema hospitalar psiquiátrico e sua hegemonia mantida, inclusive, pelos convênios com as esferas públicas.

Uma rede integrada pela presença de equipes de saúde mental em Unidades Básicas de Saúde (UBS), hospitais-dia, centros de convivência, enfermarias psiquiátricas em hospitais gerais deu suporte a uma qualitativa mudança do atendimento à saúde mental municipal.

Neste período, assim como naquele compreendido pelo Governo de Franco Montoro, houve um intercâmbio profícuo entre o Serviço de Aconselhamento Psicológico e as instituições de saúde mental municipais. Por um lado, as diversas possibilidades de acolhimento que os diferentes equipamentos ofereciam davam margem a encaminhamentos dentro do espírito do Plantão Psicológico, qual seja, o de responder adequadamente à diversidade de demandas. Por outro, a necessidade de encaminhar gerava um intenso contato com a rede, o que permitia manter atualizadas informações sobre o funcionamento das unidades, bem como incentivava a comunicação entre os profissionais, estreitando os laços de solidariedade e mútua referência. Paralelamente, alguns membros da equipe do SAP atuaram como supervisores de equipes multiprofissionais dos equipamentos da saúde mental municipais e, através dessa atividade, contribuíam para a formação de pessoal e conseqüentemente para a melhoria do atendimento. Ao mesmo tempo, funcionavam como mais um elo de ligação entre as experiências que estavam em curso na esfera municipal e a prática do Plantão Psicológico.

\footnotetext{
${ }^{8}$ Os CAPs (Centros de Apoio Psicossocial) são instituições que buscam atender integralmente os pacientes egressos de hospitais psiquiátricos ou em "primeiro surto". São pensados como espaços de referência e de convivência para uma clientela que, devido a seus transtornos emocionais, vê-se excluída da vida social e, muitas vezes, sob risco de isolamento em hospitais psiquiátricos. As atividades desenvolvidas incluem atendimento psiquiátrico e psicoterapêutico, grupos de trabalho e lazer, infra-estrutura para cuidados com a higiene, aparência, alimentação. Com o nome de NAPs (Núcleos de Apoio Psicossocial) este tipo de instituição foi central na experiência antimanicomial empreendida na cidade de Santos (SP), durante duas gestões petistas. Na cidade de São Paulo, alguns CAPs têm resistido às políticas de desmancho da rede de saúde mental, mas são claramente reduzidos em relação à demanda da clientela (Nota da autora).
} 
A passagem do governo de Luiza Erundina para o de Paulo Maluf foi marcada por um primeiro espaço de tempo, curto, de manutenção de um convênio estabelecido entre o IPUSP e a prefeitura que, entre outras coisas, permitiu a prática de supervisão acima referida. Nesse tempo, as gestões junto aos coordenadores de saúde mental do novo governo mostraram que as intenções em relação à política de saúde mental eram fazer regredir os avanços conseguidos na constituição de uma rede alternativa aos hospitais psiquiátricos. A destruição dos equipamentos logo começou a ser efetivada através de vários expedientes: suspensão das supervisões de equipes multiprofissionais com a proposta de retorno a supervisões por especialidade; volta ao atendimento ambulatorial convencional psicológico e psiquiátrico; retirada de recursos financeiros e materiais para a manutenção dos centros de convivência; transformação de hospitais-dia em ambulatórios psiquiátricos pautados pela medicalização; desvirtualização dos objetivos da internação temporária em enfermarias psiquiátricas de hospitais gerais e concomitante reativação da prática de internamento em hospital psiquiátrico; desmantelamento de equipes, entre outros.

A destruição operada na rede foi rápida e a posterior implantação do PAS consolidou a mudança. No Manual do Usuário do Plano de Atendimento à Saúde, as figuras do Centro de Convivência e Cooperativa e do Hospital-Dia em Saúde Mental aparecem nomeadas e resumidamente caracterizadas como unidades destinadas a neuróticos, psicóticos e doentes metais, impondo uma explicação sobre em que condições estas unidades permanecem ativas. Com a institucionalização do PAS, um grande número de profissionais de saúde mental (mas não exclusivamente) foi deslocado da Secretaria de
Saúde para outras Secretarias do Município por não ter "aderido" ao programa ou, mesmo, foi obrigado a pedir demissão. As unidades citadas no Manual do Usuário encontram-se, atualmente, completamente transfiguradas, conduzidas por profissionais que em sua maioria não se identificam com a luta antimanicomial, conformados ao modelo anteriormente hegemônico de atendimento hospitalar e ambulatorial com predominância de tratamento medicamentoso ${ }^{9}$. Algumas poucas unidades conservam, por motivos circunstanciais e pela ação isolada de profissionais, resquícios de uma prática norteada pelas idéias da luta antimanicomial.

Tanto na esfera estadual quanto municipal, a partir de 1993, observa-se um progressivo desmancho da rede de atendimento à saúde mental, que viveu momentos diferentes, mas igualmente importantes, de estruturação nos governos de Franco Montoro e Luiza Erundina. De uma certa maneira, a decadência da rede estadual, que se acelerou a partir do governo Fleury no plano estadual, encontrou uma compensação na efervescência das experiências realizadas no governo de Luiza Erundina. Porém, depois disso, recrudesceu a mentalidade hospitalocêntrica. Atualmente, apenas sobrevivem práticas pontuais, mantidas às custas do esforço solitário de alguns profissionais e instituições, na ausência total de políticas clara e globalmente comprometidas com a construção de uma cidade sem manicômios e com alternativas adequadas de atendimento à população que sofre.

\section{A crise da universidade pública}

Em 1989, no artigo Produtividade e humanidades, Marilena Chaui faz uma apreciação

\footnotetext{
${ }^{9} \mathrm{O}$ caso que relato a seguir ilustra, de maneira exemplar, o tipo de mentalidade que passou a dominar o atendimento à saúde mental após a implantação do PAS. Um homem de 40 anos, sofrendo de depressão em conseqüência de problemas com o trabalho, estava sendo medicado por uma psiquiatra de uma unidade do PAS. Um dos medicamentos era tomado à noite, para dormir. Um dia, segundo relato do próprio paciente, ele tomou uma dose dobrada do remédio, pois se sentia muito angustiado e com dificuldade para dormir. A família assustada com o acontecimento levou-o para uma consulta com a psiquiatra que, então, recomendou (ou "mandou") que ele fosse internado imediatamente. Diante da recusa do paciente e de seus familiares em aceitar a internação, a médica colocou-os na rua, com o argumento de que sem a internação ela não poderia se responsabilizar pelo atendimento daquele paciente. Este homem, com alguns de seus familiares, procurou o Plantão Psicológico, onde relatou sua experiência de ter sido "expulso" do PAS e demonstrou ter uma profunda clareza quanto ao tipo de ajuda que precisava e que, certamente, não era a de uma internação.
} 
crítica das propostas de modernização da universidade brasileira. Nele, destacam-se duas linhas de análise complementares. Por um lado, a denúncia dos mecanismos postos em curso para desqualificar aqueles que defendem a democratização da universidade, obliterando as possibilidades de um debate sobre o destino das instituições universitárias: o uso do termo "improdutivos"10 é emblemático na explicitação destes mecanismos. Por outro, a diferenciação entre dois modelos de modernização aplicáveis às universidades do norte e nordeste e às do sul e que se articulam, ambos, nos antípodas dos anseios de democratização das universidades brasileiras.

Sobre o uso do termo "improdutivos", e os mecanismos que abriga, cabe salientar sua ligação com um tipo de avaliação regida por critérios quantitativos, heterônima em relação ao trabalho universitário e autoritária na medida em que supõe que aqueles que detêm o poder detêm, também, o saber (Chaui, 1989). Quantitativos, heterônomos e autoritários, os critérios de avaliação que balizaram a confecção da "lista dos improdutivos" na USP foram, além disso, conservados em segredo. Como aponta Chaui (1989, p. 50), no mundo contemporâneo há dois tipos de segredos: o militar e o empresarial. E, conclui em relação aos critérios de avaliação universitária:

Se são secretos é porque têm finalidade competitiva - distribuição de recursos para ensino e pesquisa - e finalidade "bélica" - destruição dos oponentes que desconhecerem as regras do jogo.

A avaliação assim empreendida desqualifica interlocutores e, concomitantemente, torna-se instrumento de coerção, intimidação e controle na medida em que não há transparência nem dos critérios por que se pauta, nem dos critérios de "escolha" dos avaliadores. Ao longo do tempo transcorrido desde o episódio da "lista dos improdutivos", parece ter ficado escancarada a intenção de implantar a hegemonia de uma mentalidade bélica e competitiva no lugar da cooperação e da solidariedade que marcam o ideário universitário. O isolamento, a solidão e o medo instalados naqueles que teriam o que contrapor à proposta de modernização calcada no produtivismo e a adesão, refletida ou reflexa, daqueles que vêem nas proposições de um modelo empresarial a saída para a crise da universidade preparam o solo árido onde "os procedimentos de contabilidade e rendimento" vicejam.

No plano das propostas, Chaui (1989) diferencia aquela que se destina às universidades do norte e nordeste, transformando-as de "centros de ensino superior e pesquisa" em "cursos avançados de segundo grau e de formação técnico-profissional" daquela voltada para as universidades do sul e que constitui a proposta de modernização propriamente dita

Dedica-se, mais detidamente, à segunda, que é, também, a que interessa aqui comentar, pois diz respeito diretamente à situação da USP.

De início, importa dar destaque ao fato de que a proposição de modernização coloca-se em contraposição aos projetos de democratização da universidade e, coerentemente, marginaliza amplos setores universitários do debate (se é, como diz Marilena, que há debate). $O$ argumento para sua implantação reporta às "necessidades criadas pelo desenvolvimento das ciências e das humanidades". Porém, defendendo a separação entre ensino e pesquisa, direcionando o ensino para a formação dos quadros profissionais e técnicos necessários ao mercado e a pesquisa para uma adaptação "às exigências e ritmo do complexo militar ou do complexo industrial", a proposta revela-se como uma tentativa de "ajuste entre o trabalho universitário e as exigências do capital".

A separação entre ensino e pesquisa é ponto central na chamada modernização da universidade. Esta separação traz conseqüências

${ }^{10}$ Sobre o episódio da publicação, pelo jornal A Folha de São Paulo, da chamada "lista dos improdutivos", ver: Catani, A.M., Gutierrez, G.L., \& Ferrer, W.M.H. O Jornal Folha de São Paulo e a "Lista dos Improdutivos". In Dourado, L.F., \& Catani, A.M. (Orgs.). (1999). Universidade pública: políticas e identidade institucional. Campinas: Autores Associados. 
graves tanto para o ensino quanto para a pesquisa.

Na esfera do ensino, Chaui (1989) destaca dois traços que marcam essa separação: a) com o argumento de atender às singularidades, talentos e vocações dos docentes, "estimulando cada um a fazer aquilo em que é mais eficiente", tal projeto derivará numa forte hierarquização de cargos e funções e b) entregue a professores que meramente "conhecem as regras elementares de seu campo de estudo", o ensino tornar-se-á um treinamento em técnicas e comportamentos, um aprendizado normativo de modos de fazer. Sobre este segundo ponto, a autora alerta para o risco deste tipo de ensino provocar nos estudantes o gosto pelo autoritarismo - uma vez que aprender passa a ser sinônimo da adesão a regras e normas - e o conformismo.

$\mathrm{Na}$ esfera da pesquisa, parte-se, ainda segundo a autora, da constatação das injunções da ciência e da tecnologia e força produtiva, transformando esta constatação numa teoria da ciência e da tecnologia na qual se afirma que estas são "o que delas o capitalismo exige". Ou ainda, que elas devem ser o que delas exige o capitalismo. Rendem-se a esta visão propostas simplistas e sofisticadas. Como escreve Chaui (1989, p.65):

(...) algumas propostas são simplistas - estão fascinadas pela incorporação das universidades aos complexos militares e industriais -, enquanto outras pretendem salvaguardar as universidades, afirmando que, se estas não se modernizarem, serão destruídas pela formação de centros paralelos de pesquisa com polpudos financiamentos que tornarão supérfluas as pesquisas universitárias. O problema desse segundo tipo de proposta é que se coloca no mesmo campo de referências das propostas simplistas, isto é, suas referências são as necessidades impostas pelo desenvolvimento do capital, determinando a natureza da ciência e da tecnologia.

A necessidade e a normatividade do capitalismo balizam a proposta de modernização da universidade: uma das finalidades da proposta é tornar o trabalho de pesquisa brasileiro competitivo, nacional e internacionalmente. Como comenta Marilena Chaui, mesmo que a competitividade no plano internacional represente um paradoxo, considerando-se a pobreza de nossos recursos, importa destacar o lugar que a idéia de competição ocupa na proposta de modernização, como marca do que se requer do trabalho universitário. Em suas palavras:

Ora, a competição, tal como definida pela segunda natureza contemporânea, isto é, o capitalismo, possui duas determinações importantes: em primeiro lugar, é a competição contra o tempo (o tempo em sua determinação capitalista) - isto submete a pesquisa à heteronomia - e, em segundo lugar, é competição porque secreta - isto submete a pesquisa ao isolamento (Chaui, 1989, p.66) $)^{11}$.

O artigo até aqui resenhado designa a proposta de modernização da universidade como uma "tentativa de adaptar a universidade às exigências da racionalidade capitalista". No transcurso destes mais de dez anos que separam a sua publicação dos dias de hoje, muito daquilo que se apresentava, então, como proposta, foi se efetivando de modo autoritário, na ausência de um debate amplo, e através de dispositivos burocrático-administrativos aos quais as atividades cotidianas de ensino, pesquisa e extensão vêm se rendendo: a lógica do

\footnotetext{
${ }^{11}$ Boaventura de Sousa Santos, no artigo Da idéia de universidade à universidade de idéias, alerta para os riscos da adoção, pela comunidade acadêmica, da lógica industrial. Ele escreve: "O imaginário universitário é dominado pela idéia de que os avanços científicos são propriedade da comunidade científica, ainda que a sua autoria possa ser individualizada. A discussão livre dos procedimentos e etapas da investigação e a publicidade dos resultados são considerados imprescindíveis para sustentar o dinamismo e a competitividade da comunidade científica. A 'comunidade' industrial tem outra concepção de competitividade, assente nos ganhos de produtividade. Se as suas concepções se sobrepuserem às da comunidade científica, teremos, em vez de publicidade dos resultados, o secretismo, em vez da discussão enriquecedora, o mutismo sobre tudo o que é verdadeiramente importante no trabalho em curso, em vez de livre circulação, as patentes." Santos, B.S. (1999). Pela mão de Alice (p. 203) São Paulo: Cortez.
} 
produtivismo parece ter ganho sua batalha em amplos setores universitários.

Porém, o projeto desta adaptação reserva, nos dias de hoje, desdobramentos que precisam ser compreendidos em suas conexões com a Reforma de Estado que se inicia no Governo de Fernando Collor de Mello, em 1990, perde força durante o Governo de Itamar Franco e rearticula-se a partir de 1995, no Governo de Fernando Henrique Cardoso, sob o comando do Ministro Luiz Carlos Bresser Pereira (Silva Jr. \& Sguissardi, 1999).

Com Bresser Pereira, ideólogo da Reforma de Estado, o governo brasileiro tenta responder e adequar-se às diretrizes dos organismos multilaterais, dentre eles o FMI e BIRD/Banco Mundial, buscando, com isso, integrar-se ao processo de globalização. Do receituário do chamado Consenso de Washington, alguns itens dizem diretamente respeito às instituições de ensino superior: equilíbrio orçamentário através da redução de gastos públicos e a privatização de empresas e serviços públicos.

Como mostram Silva Jr. e Sguissardi (1999) em estudo inteiramente dedicado à análise das relações entre Reforma de Estado, mudança na produção e educação superior, há uma complementaridade de ações oriundas do Ministério da Administração Federal e da Reforma do Estado (MARE) e do Ministério da Educação e dos Desportos (MEC), e suas respectivas legislações, que visam enquadrar as instituições de ensino superior às reformas do Estado ${ }^{12}$.

No âmbito do MARE, as universidades são definidas, no "espírito" da reforma, como um setor de serviços não exclusivos do Estado, propondo-se a sua transformação em organizações sociais. Organizações sociais serão, segundo Bresser Pereira:

(...) organizações públicas não-estatais mais especificamente fundações de direito privado - que têm autorização legislativa para celebrar contrato de gestão com o poder executivo correspondente, fazer parte do orçamento público federal, estadual ou municipal (Bresser Pereira, 1995, p.13 apud Silva Jr. \& Sguissardi, 1999, p.34).

Sinteticamente, segundo Silva Jr. e Sguissardi (1999, p. 46), na proposta do Governo FHC:

(...) as instituições estatais de educação superior transformar-se-iam em entidades públicas de natureza privada, pode-se dizer, semipúblicas. Na proposta de Bresser Pereira, as organizações sociais submeterse-iam a três tipos de controle: estatal, comunitário e do mercado. Ao estatal, pois estariam sendo gerenciadas por meio de contratos de gestão celebrados com o Estado; ao comunitário, porque administradas por um Conselho de Administração; e ao mercado, porque a este caberia velar pela eficiência e qualidade dos serviços prestados, bem como oferecer um financiamento complementar ao oferecido pelo Estado.

No MEC, a análise da crise das universidades públicas, especialmente as federais, elege o número reduzido de vagas e o mau preparo dos universitários para o mercado de trabalho como ponto crucial. E toma o princípio de indissociabilidade entre ensino, pesquisa e extensão como origem do problema. A linha de argumentação e atuação do MEC segue, portanto, a mesma indicada por Marilena Chaui nas propostas de modernização da universidade: defesa da distinção entre universidades de pesquisa e universidades de ensino. No diagnóstico da crise efetuado pelo MEC, outros fatores "problemáticos" aparecem como decorrência do trinômio ensino/pesquisa/extensão, quais sejam: a unidade salarial; o regime de dedicação exclusiva; a isonomia entre ativos e inativos; a predominância do financiamento através de verbas públicas; falta de autonomia efetiva em virtude da dependência do Estado; o aprisionamento em tendências conservadoras; custo excessivo que

\footnotetext{
12 Uma exposição abreviada deste estudo foi também publicada, sob forma de artigo, na Revista da Associação dos Docentes da USP - Silva Junior, J.R., \& Sguissardi, V. (2000). O impacto da mercantilização da educação superior. Revista Adusp, n.19.
} 
onera governos estaduais e federal; falta de qualidade e equidade (Silva Jr. \& Sguissardi (1999).

Os remédios sugeridos pelo MEC incluem, além da diferenciação entre instituições de ensino e de pesquisa, a diversificação das fontes de financiamento, a introdução do ensino pago, estabelecimento de convênios com a iniciativa privada, sistema de avaliação norteado pela adequação às demandas de mercado, facilitação do desenvolvimento das instituições de ensino privado.

À guisa de síntese, escrevem Silva Jr. e Sguissardi (1999, p.70) que:

Tanto as medidas implementadas pelo MARE, quanto as de iniciativa do MEC parecem apontar para um gradativo afastamento do Estado das responsabilidades constitucionais de manutenção desse serviço público estatal e indução à busca de recursos para sua manutenção junto a fontes privadas, incluindo-se a adoção do ensino pago. Apontam também na direção de gradativa transformação das IES em universidades de ensino, do fim da carreira docente nacional e da matriz salarial isonômica e conseqüente implantação de regimes precarizados de trabalho nas IFES $^{13}$.

Ao concluírem a análise das propostas sugeridas pelo Banco Mundial, encampadas pelo MARE e pelo MEC, os autores indagam se o caminho de diferenciação institucional, privatização e concomitante retirada do Estado servirão aos propósitos de superação da crise, considerando-se, por um lado, a tradição de baixa qualidade do ensino superior privado e, por outro, a precária situação socioeconômica daqueles que hoje encontram-se excluídos das universidades, num país com péssima distribuição de renda.

Numa perspectiva, também crítica, de exame da inserção das universidades na Reforma de Estado, Marilena Chaui, em artigo publicado em 1999, dispõe-se a responder à indagação sobre o que significa, para a universidade, passar da condição de instituição social à de organização social.

Chaui (1999) começa por estabelecer uma diferença básica entre instituição e organização social, qual seja: enquanto a instituição social coloca-se, a si mesma, a questão sobre sua razão de ser em relação à sociedade na qual se insere, uma organização social é instrumental, referida "ao conjunto de meios particulares para obtenção de um objetivo particular". Num parágrafo, Chaui (1999, p. 280) expõe aquilo que fundamentalmente separa a instituição social de uma organização. Ela escreve:

A instituição social aspira à universalidade. A organização sabe que sua eficácia e seu sucesso dependem de sua particularidade. Isso significa que a instituição tem a sociedade como seu princípio e sua referência normativa e valorativa, enquanto a organização tem apenas a si mesma como referência, num processo de competição com outras que fixaram os mesmos objetivos particulares. Em outras palavras, a instituição se percebe inserida na divisão social e política e busca definir uma universalidade (ou imaginária ou desejável) que lhe permita responder às contradições impostas pela divisão. Ao contrário, a

\footnotetext{
13 Não se sabe, ao certo, o que se prepara para as universidades estaduais de São Paulo, entre elas a USP. O arrocho salarial como forma de pressão para a aceitação de uma política de premiações e aumentos diferenciados, a degradação do RDIDP, a proliferação das Fundações que engolem os Departamentos e concentram forte poder econômico e de mando, a efetiva privatização de um conjunto significativo de atividades, a penúria de recursos de algumas áreas em contraposição à opulência de outras, entre outros aspectos, formam o cenário no qual as diferenças de prestígio, reconhecimento e econômicas aparecem claramente. Ao tratar do lugar das humanidades nas propostas de modernização da universidade, Chaui (1989) afirma o seguinte: "Visto que não há como propor para as humanidades sua perfeita adequação ao mercado de trabalho nem sua inserção direta nas forças produtivas, o argumento acerca do baixo nível e da irracionalidade das humanidades conduz a uma proposta precisa: cortá-las ao máximo" (p.67). É possível, pois, que uma parte da USP, justamente aquela composta pelas humanidades, esteja destinada a transformar-se em "colégios" e outra, aquela que tem "talento para os negócios", se firme como centro de pesquisa.
} 
organização pretende gerir seu espaço e seu tempo particulares aceitando como dado bruto sua inserção num dos pólos da divisão social, e seu alvo não é responder às contradições, e sim vencer a competição com seus supostos iguais.

Ainda segundo a autora, a sociedade para o capitalismo atual aparece como uma espécie de conglomerado de organizações particulares com objetivos e estratégias particulares competindo entre si. A sobrevivência de uma organização não depende de sua estrutura interna, mas de sua capacidade de adaptar-se às mudanças rápidas e intensas "da superfície do 'meio ambiente'”: "a organização pertence à ordem biológica da plasticidade do comportamento adaptativo".

A passagem da universidade de instituição social para organização vem na continuidade do projeto de sua adaptação às exigências do capitalismo, presentes já nas propostas de modernização, correspondendo a uma etapa que Chaui (1999) denomina universidade operacional. Posterior à universidade funcional - pautada pela formação de profissionais qualificados para 0 mercado de trabalho - a universidade operacional é definida, por comparação com a universidade clássica e funcional, nos seguintes termos:

(...) enquanto a universidade clássica estava voltada para o conhecimento e a universidade funcional estava voltada diretamente para o mercado de trabalho, a universidade operacional, por ser uma organização, está voltada para si mesma como estrutura de gestão e de arbitragem de contratos. Regida por contratos de gestão, avaliada por índices de produtividade, calculada para ser flexível, a universidade está estruturada por estratégias e programas de eficácia organizacional e, portanto, pela particularidade e instabilidade dos meios e dos objetivos. Definida e estruturada por normas e padrões inteiramente alheios ao conhecimento e à formação intelectual, está pulverizada em micro-organizações que ocupam seus docentes e curvam seus estudantes a exigências exteriores ao trabalho intelectual. A heteronomia da universidade autônoma é visível a olho nu: o aumento insano de horas-aula, a diminuição do tempo para mestrados e doutorados, a avaliação pela quantidade de publicações, colóquios e congressos, a multiplicação de comissões e relatórios etc. Voltada para seu próprio umbigo, mas sem saber onde este se encontra, a universidade operacional opera e por isso mesmo não age (Chaui, 1999, p. $281)^{14}$.

$\mathrm{Na}$ esfera do ensino, a universidade operacional coloca a transmissão de informação e o treinamento no lugar da formação. Na esfera da pesquisa, Chaui (1999, p. 284) pergunta-se sobre a transformação da pesquisa num contexto ideológico, autodenominado pós-moderno, em que razão, verdade e história são consideradas mitos, e espaço e tempo, a superfície de surgimento intermitente de imagens, pensamento e linguagem. A pesquisa transforma-se em "survey de problemas, dificuldades e obstáculos para a realização do objetivo, e um cálculo de meios para soluções parciais e locais para problemas parciais e locais". Aqui, ainda, os "pesquisadores" se transmutam em gestores de contratos e programas, sendo valorizadas suas aptidões para a busca de recursos financeiros e sua capacidade administrativa no uso desses recursos.

\footnotetext{
${ }^{14}$ Robert Musil, no livro anteriormente citado, faz um conjunto de observações sobre a relação entre um estado de desorientação e a substituição da ação qualificada pela sua quantidade. Em suas palavras: "Esta forma de ação é a da absoluta desorientação; desprovida do plano, parece que a razão, como todo e qualquer instinto de salvação, a abandonou; mas seu plano inconsciente consiste em substituir a qualidade das ações pela sua quantidade, e a sua astúcia, que nada tem de medíocre, baseia-se na probabilidade que em cem tentativas cegas, que passam ao lado do alvo, haver uma que o atinge. (...) Trata-se, por outras palavras, de substituir uma acção intensiva por uma acção extensiva, e nada mais humano do que substituir a adequação dos termos das acções pela sua quantidade" (p.25). É, talvez, sob a égide do pânico e da desorientação, que a universidade opere presentemente, no abandono, como pontua ironicamente Musil, da razão e de qualquer instinto de salvação.
} 
A autora não se furta a expor aquilo que entende como pesquisa, em contraposição a survey: interrogação, reflexão, crítica, enfrentamento do instituído, descoberta, invenção e criação; trabalho de pensamento e de linguagem para pensar e dizer o que não foi pensado, nem dito; visão compreensiva de totalidades e sínteses abertas; ação civilizatória contra a barbárie social e política.

Concluindo, Chaui (1999, p.285) afirma que a universidade operacional:

(...) não forma e não cria pensamento, despoja a linguagem de sentido, densidade e mistério, destrói a curiosidade e a admiração que levam à descoberta do novo, anula toda pretensão de transformação histórica como ação consciente dos seres humanos em condições materialmente determinadas.

A crítica de Minto, Kawashita e Camargo (2000, p. 56) endereçada à universidade concebida como organização social, na qual o ensino deve se dissociar da pesquisa, aponta a diferenciação entre pensar e fazer, construir e reproduzir, criar e consumir como marca desta dissociação. Enfatiza, ainda, na mesma direção da crítica empreendida por Marilena Chaui, o quanto a adoção, como critério para a produção acadêmica, da racionalidade tecnoburocrática subordinada aos interesses do mercado está no lugar da busca do "desconhecido na perspectiva de universalizar os direitos civis, políticos e sociais".

Esses autores indicam O Plano Nacional de Educação - Proposta da Sociedade Brasileira - como o projeto que se contrapõe àquele do MEC. Para esse projeto, as universidades:

(...) constituem-se num patrimônio social e são caracterizadas por um padrão unitário de qualidade, a partir da indissociabilidade entre ensino, pesquisa e extensão e pela universalidade na produção e transmissão de conhecimentos e experiências em todas as suas dimensões (artística, científica, cultural, tecnológica, etc.) (Minto, Kawashita e Camargo, 2000, p. 60).
A crise da universidade pode ser compreendida através do embate entre a avassaladora implementação de dispositivos burocrático-administrativos que visam transformá-la plenamente em uma organização social e a resistência exercida por aqueles que "apostam numa nova hegemonia", pautada pelo desejo de construir uma universidade democrática, crítica, pluralista e, portanto, referida à sociedade na qual se insere. Na construção de uma universidade democrática entram em jogo, como afirmam Minto, Kawashita e Camargo (2000, p.61), "a recuperação do Estado como provedor de direitos civis, políticos e sociais" e a constituição da universidade como locus "da produção de conhecimentos e de crítica aos governos e às políticas que não contemplam os interesses da maioria da população".

\section{A extensão universitária e os serviços de atendimento à comunidade}

Como conjunto de práticas privilegiadas de contato com a sociedade, a extensão e os serviços universitários podem-se constituir vias de mão dupla através das quais a universidade serve à sociedade e, ao mesmo tempo, recebe desta tanto uma avaliação sobre a relevância e adequação do conhecimento que produz, quanto uma radiografia das demandas a ela dirigidas. Não sendo as únicas práticas de intercâmbio com a população, são, contudo, preciosas oportunidades de inclusão da universidade na sociedade e de recepção da sociedade na universidade.

As atividades de extensão e os serviços universitários começaram a ser debatidos e implantados na década de sessenta, nos Estados Unidos, onde respondiam a ideários diversos, muitas vezes antagônicos, tendo sido alvos de críticas tanto por parte de setores conservadores das universidades quanto por parte de setores estudantis (Santos, 1999).

Boaventura de Sousa Santos, discutindo a crise de hegemonia da universidade, desenha a trajetória da proposta de extensão universitária, destacando suas vertentes, tensões, bem como 
as críticas a ela endereçadas, no contexto americano. Essa análise, que aborda também alguns desdobramentos do modelo americano nas universidades da América Latina e, em especial, o caso da Universidade de Brasília, mostra-se útil no sentido de desnudar a coexistência de diferentes concepções de extensão praticadas num mesmo ambiente universitário, a exemplo do que ocorre na USP.

De acordo com Santos (1999), a ideologia universitária pautada pela investigação desinteressada e autônoma da verdade, que priorizava a pesquisa e a teoria em detrimento da prática, entra em crise a partir do pós-guerra. Nos anos sessenta, acirram-se as reivindicações de um comprometimento das universidades na resolução de problemas sociais e econômicos. A extensão universitária, como modo de corresponder a estas reivindicações, desemboca em pelo menos duas vertentes que precisam ser diferenciadas: uma economicista e produtivista, voltada para o acréscimo de produtividade industrial, e outra, crítica, que discute o papel da universidade no enfrentamento dos problemas sociais e na "valorização social e cultural da comunidade envolvente". Para a primeira vertente, "comunidade" é sinônimo de empresas e indústrias ${ }^{15}$. Para a segunda, existe a necessidade de definir a esfera de compromissos sociais e políticos: mundial, nacional ou local. Como escreve Santos (1999, p.206) no debate dos anos sessenta sobre o envolvimento da universidade com os problemas sociais:

(...) para alguns a universidade devia comprometer-se com os problemas mundiais em geral e onde quer que ocorressem (a fome no terceiro mundo, o desastre ecológico, o armamentismo, o apartheid etc.), para outros, o compromisso era com os problemas nacionais (a criminalidade, o desemprego, a degradação das cidades, o problema da habitação etc.) ou mesmo com os problemas regionais ou locais da comunidade imediatamente envolvente (a deficiente assistência jurídica e assistência médica, a falta de técnicos de planejamento regional e urbano, a necessidade de educação de adultos, de programas de cultura geral e de formação profissional etc.).

Um ponto importante, portanto, de se reter da análise feita por Boaventura de Sousa Santos diz respeito à grande elasticidade do apelo à prática e das concepções de responsabilidade social da universidade. Embora, como afirma esse autor, uma idéia mais ampla de responsabilidade social, implicando a valorização das comunidades e a proposição de intervenções reformistas, continue viva no imaginário universitário, é necessário pontuar que o avanço da mentalidade organizacional na universidade reforça, sobremaneira, a vertente que reduz a responsabilidade social às relações com a indústria e o mercado.

Como alerta Romano (2000), as chamadas "consultorias" e seus convênios, através da extensão, têm se tornado cada vez mais importantes para captar recursos com os quais professores e pesquisadores buscam aumentar seus salários e mesmo financiar meios de trabalho. Algo semelhante pode ser observado em relação a cursos de aperfeiçoamento e especialização que são ministrados com os intuitos acima mencionados.

Do ponto de vista do "financiamento" de salários, essa visão da extensão cria, no plano ético:

(...) professores de classes distintas: os de "primeira", que podem obter excelentes (em termos financeiros) convênios, os que atingem tratos menos lucrativos, e um proletariado professoral, sem direitos ou esperanças, que tende a crescer em termos numéricos (Romano, 2000, p.87).

Porém, há, também, um outro conjunto de efeitos, ligados a este anteriormente citado, que diz respeito à submissão das atividades de

\footnotetext{
${ }^{15}$ Os representantes da comunidade no Conselho Universitário da USP são, usualmente, membros de entidades do comércio e da indústria.
} 
extensão a interesses de mercado. A prospecção de demandas por serviços e cursos com chances de sucesso mercadológico passa a ter mais relevância do que o debate crítico sobre prioridades políticas, sociais e culturais. Por outro lado, na medida em que as reitorias se retiram do financiamento de infra-estrutura para realização de atividades de extensão que não encontram "financiadores", ou porque não são lucrativas ou porque não interessam politicamente aos gestores do mercado, estas tendem a minguar. Alguns serviços das áreas de saúde e educação, a exemplo do Plantão Psicológico, voltados para populações de baixa renda, têm pouca ou nenhuma chance de auferir recursos através de convênios com instituições estatais ou privadas: as estatais estão se desvencilhando da responsabilidade de prover saúde e educação ${ }^{16} \mathrm{e}$ as privadas só se interessam por saúde e educação quando estas se transformam num "bom negócio". As reitorias, por seu turno, sinalizam, claramente, que cabe aos docentes desses setores buscar os recursos necessários à sua manutenção: não fazer, ou não conseguir, é sinal de incompetência ou do obsoletismo do setor.

A transformação das atividades de extensão e dos serviços em formas de captação de recursos financeirosé um fenômeno que denuncia o avanço da privatização $0^{17}$ no âmbito das universidades públicas, a exemplo do que já vem ocorrendo na USP, onde as instâncias de avaliação só reconhecem e valorizam as iniciativas que trazem dinheiro à universidade e "toleram", sem, no entanto, sequer reconhecer como academicamente relevantes aquelas que não "oneram" os cofres universitários.

O comentário feito em relação à pesquisa, ou seja, o de que as áreas afeitas à aplicação tecnológica que interessa às indústrias serão financiadas e, portanto, terão como sobreviver, enquanto que as áreas de produção de conhecimento crítico morrerão à mingua, na concepção organizacional da universidade, é também pertinente para a situação da extensão e dos serviços, especialmente quando comprometidos com a pesquisa e o ensino voltados para a compreensão e a superação dos graves problemas das populações marginalizadas econômica, política e socialmente.

Tendo como cenário as idéias esboçadas em torno da situação das políticas públicas para a saúde, da crise da universidade e da especificidade dos serviços de extensão, retoma-se, então, a análise do Plantão Psicológico.

\section{Os impasses atuais do Plantão Psicológico}

O Plantão Psicológico comporta-se como uma porta de entrada para o Serviço de Aconselhamento Psicológico: uma porta de entrada suficientemente ampla para que se possa ter contato com a pluralidade dos modos através dos quais a clientela abre e tematiza seu sofrimento, bem como encaminha um pedido de ajuda.

\footnotetext{
${ }^{16}$ O Serviço de Aconselhamento Psicológico tem por tradição colaborar com instituições públicas, através de convênios. Esses, contudo, não envolveram, até o presente momento, nenhuma captação de recursos. Através deles, o SAP oferece um programa de intervenção, e a contrapartida da instituição é a oportunidade de inserir no programa alunos de graduação e pós-graduação que, atuando voluntariamente, trabalham para aperfeiçoar sua formação.

17 Em debate ocorrido em 9 de maio de 2000, no IPUSP, sobre as atividades de extensão, a explicitação do que se entende por privatização dos serviços universitários foi um dos pontos mais polêmicos. Maria Cristina Machado Kupfer, docente do Instituto, na ocasião, fez um conjunto de observações pertinentes que cabe aqui resenhar. Em primeiro, a distinção entre a privatização do público e o legítimo investimento privado nos empreendimentos públicos. Em segundo, a lógica perversa que empurra para docentes e funcionários a função de captar recursos para garantir a continuidade dos serviços universitários, públicos. Sobre o primeiro ponto, convém comentar que, de fato, não seria ilegítimo cobrar de empresas e indústrias, que obtêm lucros consideráveis, uma participação em projetos de importância social e cultural. Um problema parece residir, entre outros aspectos, na inexistência de uma política ou projeto social que indique as prioridades e obrigue o capital privado a investir nessas prioridades: empresas e indústrias investem naquilo que lhes interessa e, muitas vezes, com finalidade meramente publicitária. Ao mesmo tempo, estes investimentos não são contínuos. Sobre o segundo ponto, destaca-se, justamente, a retirada do Estado e das Reitorias (no caso específico dos serviços de extensão) do financiamento de atividades e setores cuja existência só pode ser garantida na esfera de investimentos públicos.
} 
Em sua inserção numa clínica-escola, o Plantão Psicológico é, também, uma forma de consubstanciar a crítica a uma mentalidade que concebe a clínica-escola como lugar de treino e de aplicação de modelos e técnicas psicológicos consagrados e que adere a uma intensa institucionalização e burocratização das formas de transmissão do saber, bem como das práticas de atendimento, e, na qual, anula-se o espírito de investigação. Esse contraponto crítico tem como base, justamente, a inclusão do espírito investigativo e a pesquisa como mediações fundamentais na articulação entre formação e prestação de serviços à comunidade ${ }^{18}$. A prática do Plantão Psicológico tem como uma de suas metas a constituição da clínica-escola como lugar de criação e invenção. Os alunos/estagiários são convidados a compor, junto com o grupo de quatro docentes e quatro técnicos (três psicólogas e um psiquiatra), uma equipe ampliada que atende à clientela, buscando retomar constantemente recursos teórico-práticos e questionandoos quando se mostram a serviço do saber constituído, da dominação e da exclusão. A reflexão teórica, a pesquisa empírica e a experiência de atendimento são concebidas como esferas indissociáveis, alimentando-se e iluminando-se mutuamente.

Estas observações sumariam uma espécie de ideário ao qual o Plantão Psicológico procura corresponder: trata-se de um projeto, de um propósito, de um guia conceitual para as ações, de um horizonte ideal.

Historicamente, o Plantão Psicológico foi se constituindo um campo de experimentação na área do atendimento psicológico, e esta experimentação teve, como metas complementares, a formação de psicólogos comprometidos com uma postura crítica e investigativa em relação à saúde pública e à produção de saberes e modos de intervenção adequados à população que recorre aos serviços públicos de saúde. O projeto clínico-pedagógico do Serviço de Aconselhamento Psicológico, no qual o Plantão se insere, tem como eixo a formação de psicólogos capazes de se engajar competente e criativamente na esfera das instituições públicas de saúde porque, ideologicamente, defendem que uma universidade pública tem como papel social formar profissionais com espírito investigativo cujo trabalho ganha sentido abraçando as causas coletivas.

Um dos fatores que informa a crise de parâmetros que o projeto clínico-pedagógico do SAP vive atualmente diz respeito, justamente, à descontinuidade das relações entre este e as políticas estatais de saúde: as instituições públicas de saúde, submetidas ao desmantelamento, não se encontram mais em condição de dialogar com o saber produzido neste âmbito universitário e não absorvem os profissionais que aí se formam.

Neste plano, a crise de parâmetros leva à reflexão sobre o impasse criado entre insistir na parceria com as instituições públicas de saúde ou afastar-se das áreas públicas governamentais e buscar uma aproximação com setores organizados da sociedade que procuram, de alguma forma, "cobrir" os rombos destas áreas, na prestação de serviços de saúde, como, por exemplo, sindicatos, sociedades de amigos dos bairros, paróquias, cooperativas. Esse impasse coloca uma questão de fundo que precisa ser enfrentada, pois da resposta a ela dependerá o encaminhamento de ações políticas em uma ou outra direção, no embate com a proposta neoliberal para as instituições de saúde (e de educação). A pergunta é: quais as conseqüências sociais e políticas de se criarem redes de atendimento que "substituam" os equipamentos públicos, admitindo, pois, que cabe à sociedade organizada dar conta das tarefas de cuidado à

${ }^{18}$ Para uma visão mais detalhada desta discussão sobre a articulação entre ensino, pesquisa e prestação de serviço em clínicas-escola ver: Schmidt, M.L.S. (1992) Clínica-escola, escola da clínica? Boletim de Psicologia. Sociedade de Psicologia de São Paulo, 42 (96/97), Jan/Dez. 
saúde ${ }^{19}$ No caso em que se escolha investir na criação de "redes substitutas", é cabível ainda perguntar qual a contrapartida que se deve esperar e cobrar das instâncias governamentais?

No âmbito das relações internas à universidade há, ainda, desdobramentos da crise que precisam ser examinados e que requerem uma abordagem psicossocial.

No modelo produtivista e organizacional da universidade estão presentes elementos já identificados e analisados na chamada reestruturação produtiva no terreno das empresas e indústrias: por um lado, a imposição ideológica de um consenso em torno da inevitabilidade dos processos em curso e, por outro, a adoção de princípios tais como a excelência correspondendo ao ganho em competitividade, a flexibilização das relações de trabalho, a polivalência (Seligmann-Silva, 1999). Esses princípios não se evidenciam tão claramente no discurso dos gestores da universidade e assumem formas de implementação matizadas pelas especificidades das universidades públicas, embora os efeitos de sua aplicação assemelhem-se àqueles que Edith Seligmann-Silva descreve em relação a empresas.

A instabilidade, a incerteza sobre o futuro e a ausência de reconhecimento do trabalhador através de seu trabalho, resultantes da flexibilização das relações sociais de trabalho, estão presentes no cotidiano de docentes e funcionários, mas no caso da universidade, as avaliações quantitativas e autoritárias fazem as vezes da flexibilização que, por sua vez, parece estar no horizonte do que seria desejável para a universidade organizacional.

Um outro conjunto de efeitos ligados à polivalência também pode ser transposto para a realidade universitária: a sobrecarga de trabalho num espectro bastante diversificado de atividades; a invasão do espaço de vida privado por tarefas a serem executadas após a jornada de trabalho; o apagamento do interesse e do sentido do trabalho; a valorização da rapidez e fluidez dos contatos interpessoais em detrimento das possibilidades de diálogo e reflexão conjunta, entre outros.

No que diz respeito à equipe que coordena e conduz o Plantão Psicológico, a exigência de polivalência é expressiva: os docentes e os técnicos (psicólogas e psiquiatra) dedicam-se, diretamente, às atividades de ensino através das aulas e supervisões de estagiários ${ }^{20}$, realizam pesquisa e atendem à clientela. A sobrecarga, no entanto, advém: a) das exigências burocráticoadministrativas que se tornam cada vez maiores, tanto para o funcionamento do SAP, quanto para os membros da equipe, individualmente, na relação com as instâncias de poder na universidade (departamento, diretoria, comissões de avaliação entre outras); b) da necessidade de prover meios para a realização de atividades básicas, desde que, como afirmado anteriormente, os recursos de pessoal e materiais tornaram-se cada vez mais limitados e c) do desejo de

\footnotetext{
19 O SAP mantém, já há uns quatro anos, um cadastro de profissionais conveniados (em sua maioria ex-alunos do IPUSP), que atendem alguns clientes encaminhados a partir do Plantão Psicológico, cobrando de $0 \%$ a $20 \%$ do salário mínimo por sessão de psicoterapia. Essa iniciativa, de certa forma, responde positivamente à pergunta formulada, pois se trata de oferecer uma alternativa àqueles que não encontram mais atendimento na rede pública. Os encaminhamentos são feitos a partir de critérios conversados com a clientela e que incluem o lugar de moradia do cliente, sua necessidade psicológica no momento, sua impossibilidade de pagar pelo serviço e a ausência de atendimento público adequado, entre outros. Do ponto de vista humanitário, por assim dizer, a iniciativa é legítima, pois oferece uma oportunidade das pessoas receberem atendimento psicológico adequado gratuito ou pagando uma quantia que lhes é viável, numa circunstância em que, para cada uma delas, não é possível esperar pelas mudanças desejáveis nas políticas públicas. Politicamente, contudo, é preciso admitir que iniciativas como essa "aliviam" a pressão que se exerceria sobre os serviços públicos para que assumam sua responsabilidade social.

${ }^{20}$ O Setor de Aconselhamento Psicológico tem sob sua responsabilidade duas disciplinas obrigatórias e uma optativa para o curso de graduação, sendo que as três oferecem estágios. A supervisão de estagiários, feita em grupos, requer a participação de todos da equipe, uma vez que é recomendável que os grupos tenham, no máximo, oito ou dez alunos cada um. Muitas vezes, para conseguir essa condição aceitável, mas de maneira nenhuma ideal, recorre-se a alunos de pós-graduação que, através do Projeto de Aprimoramento no Ensino (PAE), participam das disciplinas como supervisores de estágio.
} 
responder a uma diversidade de demandas que se constelam a partir do Plantão Psicológico, recobrindo o atendimento à clientela e as instituições e grupos que solicitam intervenções fora da USP, a pesquisa de temas e fenômenos que ali se abrem à interrogação, a solicitação de alunos de graduação que querem ampliar sua participação no SAP para além das atividades regulares do currículo, a necessidade de divulgar e transmitir o conhecimento e a experiência acumulados para profissionais e pesquisadores interessados nesta prática. As demandas elencadas nesse último item são, sem dúvida, responsabilidade da equipe e só passam a compor o quadro de uma sobrecarga na medida em que: a) a equipe se torna reduzida em relação ao montante das demandas em sua diversidade, quantidade e gravidade; $b$ ) a provisão dos meios para a realização dos trabalhos de pesquisa, atendimento e formação passa a depender, em grande parte, da iniciativa dos membros da equipe; c) falta reconhecimento e apoio efetivos, por parte das instâncias gestoras da universidade, que limitam recursos financeiros, recusam a contratação de novos docentes e técnicos e atribuem um valor praticamente nulo às atividades do setor por ocasião das avaliações; d) o cotidiano de trabalho, regido pela necessidade de atender o mais extensiva e adequadamente às demandas locais, acaba por confinar a equipe num circuito de ações reativas a situações vividas freqüentemente como emergenciais ${ }^{21}$.

Numa visada psicossocial, é possível identificar, na equipe, sentimentos que espelham, até certo ponto, o que a própria clientela que recorre ao Plantão Psicológico exibe: desamparo, isolamento, cansaço, angústia.
O desamparo está fortemente relacionado, por um lado, à precariedade dos recursos de saúde mental na cidade de São Paulo ${ }^{22} \mathrm{e}$, por outro, à ausência de reconhecimento e apoio (econômico, técnico e administrativo) no âmbito interno da universidade ${ }^{23}$.

O isolamento apresenta-se sob diferentes facetas: como defesa em relação ao excesso de exigências, como resultado da imersão na rotina de trabalho ou, ainda, nas tentativas empreendidas pela equipe de, por si só e solitariamente, superar as dificuldades, fechando-se em torno de uma hiperlocalização dos problemas.

O cansaço, como aponta Seligmann-Silva (1999), advém do aumento de esforços para atender ao conjunto de exigências, esforços que se somam à auto-exigência de manter o controle emocional e não demonstrar o próprio cansaço, irritação ou raiva. Esta exigência de autocontrole emocional é particularmente contundente quando se considera o relacionamento com a clientela, com alunos e com os próprios colegas.

A angústia que, positivamente, enseja o pensamento e move o grupo no sentido de não se render à acomodação, abandonando seus propósitos, é, talvez, mais fortemente provocada no contato com a clientela. A clientela que chega ao Plantão Psicológico, na maioria das vezes, individualmente, desenha, através de seu sofrimento pessoal, a paisagem da dura realidade social em que vive. A identificação com a clientela obriga a uma visão das raízes sociais de seu sofrimento. Porém, assim como para a clientela advém o momento em que precisa recorrer à ajuda de um profissional de saúde, não encontrando em seu ambiente social quem sustente sua angústia, para aqueles que se

^ Tornou-se rotina a presença de um grande número de clientes no Plantão Psicológico, bem como, em contrapartida, orientar um grande número de atendimentos em cada sessão de supervisão. É usual, também, correr com o preenchimento de formulários para encaminhar pedidos de monitores e bolsistas (PIBIC, Trabalho, PAE) para contar com pequena ampliação, temporária, da equipe. É corriqueiro o recurso ao trabalho voluntário de alunos e ex-alunos que ajudam na informatização do SAP, no envio de correspondência, na programação e organização de cursos de extensão, na elaboração de projetos de pesquisa etc.

22 Maria Cristina Rocha, psicóloga do SAP, reportou que há algum tempo tinha abandonado a prática de telefonar para as instituições públicas de saúde em busca de um encaminhamento, pois era desanimador constatar, a cada vez, a dimensão do desmantelamento da rede de atendimento à saúde mental.

³ O reconhecimento da relevância social do projeto clínico-pedagógico articulado em torno do Plantão Psicológico vem, sobretudo, dos alunos e de parte significativa da clientela. 
propõem acolhê-la, a necessidade de sustentação da angústia que conduz ao pensar e ao agir conseqüentes se faz presente.

No panorama delineado pelas tendências hegemônicas na saúde pública e na universidade, o Plantão Psicológico é uma prática de resistência e não pode, nem deve, esperar dessas políticas a sustentação que requer. Por essa razão, a discussão sobre saídas para a sua situação atual pede, para além da consideração de iniciativas hiperlocalizadas, uma confrontação ética, teórica e prática com essas políticas.

\section{A confrontação como saída}

A título de conclusão, segue-se uma espécie de pauta de reflexões e ações que pode ajudar a enfrentar a crise experimentada pelo Plantão Psicológico.

Em relação às políticas públicas de saúde, parece imprescindível que o Serviço de Aconselhamento Psicológico procure dialogar com os setores de atendimento à saúde mental que mantêm o ideário da luta antimanicomial. Esse diálogo é importante para obter, primeiramente, informação sobre as eventuais formas de organização dos trabalhadores de saúde mental que se mantêm ativas e para retomar e estreitar os intercâmbios políticos e profissionais. A confrontação com as políticas de cunho neoliberal para a saúde requer a articulação do maior número possível de profissionais, instituições e entidades representativas (sindicatos, conselhos) em torno da produção teórico-crítica, da elaboração de propostas e da luta por mudanças substanciais.

Na universidade, há pelo menos dois territórios vitais para serem ocupados. O primeiro é o da luta pela democratização da universidade em três frentes: a democratização das estruturas de poder universitário, pois a estrutura atual, autoritária, tem permitido a implantação e o avanço da mentalidade produtivista e do modelo organizacional; a democratização do acesso à universidade e a democratização das relações da universidade com a sociedade, repondo-se, constantemente, a interrogação sobre sua função social ${ }^{24}$.

O segundo é o da revitalização do espírito e da convivência universitárias. Os dispositivos produtivistas funcionam de modo avassalador na obstrução do debate e do diálogo e, ao mesmo tempo, corroem os laços de solidariedade e cooperação, incentivando a competição e a destrutividade na relação entre pares. Parece, portanto, fundamental "cavar", cotidianamente, os espaços de encontro e empreender, periodicamente, a suspensão da rotina como possibilidade de se situar diante do que vive a universidade ${ }^{25}$.

No que se refere às atividades e serviços de extensão, é preciso enfatizar o quanto vêm servindo à captação de recursos financeiros, desvinculando-se, muitas vezes, do ensino e da pesquisa e descaracterizando-se como conjunto de práticas privilegiadas através das quais a universidade é convocada a pensar e a agir com responsabilidade social.

Para as disciplinas em que a existência de serviços de extensão é indispensável, como a psicologia, os serviços podem e devem se pautar pela exemplaridade e pela experimentação, indicando possibilidades de avanço e melhoria das práticas de atenção à população, nas áreas de saúde, educação e do trabalho e buscando formar profissionais e pesquisadores solidários

\footnotetext{
${ }^{24}$ Boaventura de Sousa Santos, no artigo já citado, defende a tese de que a universidade ocupa uma posição privilegiada para criar comunidades interpretativas, a partir do encontro de saberes científicos, populares e do senso comum. Para este autor, "a democratização da universidade mede-se pelo respeito ao princípio da equivalência dos saberes e pelo âmbito das práticas que convoca em configurações inovadoras de sentido. A universidade será democrática se souber usar o seu saber hegemônico para recuperar e possibilitar o desenvolvimento autônomo de saberes não-hegemônicos, gerados nas práticas das classes sociais oprimidas e dos grupos ou estratos socialmente discriminados" (Santos, 1999, p.228). Essa tese merece ser debatida e aprofundada em sua conexão com as atividades de extensão.

${ }^{25}$ No momento de finalização desse artigo, as três universidades estaduais de São Paulo estão em greve. O estado de greve tem chamado a atenção de estudantes, funcionários e professores para o grau de deterioração e aridez das relações interpessoais no campus universitário, ao mesmo tempo em que propicia uma revitalização dessas mesmas relações na circunstância excepcional que cria.
} 
com as causas populares. Nessa perspectiva, a chamada prestação de serviço - incluindo atendimento direto a indivíduos, grupos e instituições e assessorias a órgãos públicos ou privados - é, a um só tempo, oportunidade de uma ação social informada pela construção do saber acadêmico, ocasião de aprendizagem para estudantes, técnicos e docentes e guia na escolha de temas e de fenômenos para a pesquisa. Não parece razoável, nem aceitável, reduzir a extensão à função de auferir lucros financeiros para a universidade. Uma inversão opera-se: ao invés da universidade prover os meios para que os serviços cumpram sua função na construção do saber e na formação dos estudantes, os serviços são compelidos a buscar os meios de manterem-se a si mesmos e à universidade, pois uma boa parte do dinheiro que já ingressa na universidade, através dos serviços, fica retida na reitoria. Essa situação obriga, por um lado, a um amplo debate sobre temas tais como a cobrança dos serviços, os convênios, a criação de fundações e, por outro, à reivindicação de que as instâncias administrativas da universidade destinem recursos suficientes para a manutenção dos serviços de extensão.

Essa pauta indica, claramente, que enfrentar os problemas atuais do Plantão Psicológico requer confrontar as políticas públicas para a saúde e para a educação e o projeto hegemônico de uma universidade organizacional, tarefa que cabe a coletivos bem mais amplos do que aquele da equipe que o coordena. Por essa razão, requer, antes de mais nada, a transposição do trabalho isolado e enquistado de indivíduos e grupos, imposto pelos dispositivos burocráticoadministrativos no interior da universidade.

No terreno estritamente relativo à proposta de Plantão Psicológico há, ainda, uma observação a ser feita e que no contexto atual mereceria atenção. Trata-se do modelo predominantemente individual de atendimento da clientela.

\section{REFERÊNCIAS}

Chaui, M. (1989). Produtividade e humanidades. Tempo Social: Revista de Sociologia da USP, 1 (2), 45-71.
Chaui, M. (1999). A universidade hoje. In F. Aguiar (Org.). Antonio Candido: pensamento e militância. São Paulo: Fundação Perseu Abramo.

Mahfoud, M. (1987). A vivência de um desafio: plantão psicológico. In R.L. Rosenberg. Aconselhamento psicológico centrado na pessoa. São Paulo: EPU.

Minto, C.A., Kawashita, N., \& Camargo, R.B. (2000). Caminhos e descaminhos da docência. Revista ADUSP, 19, 54-61.

Morato, H.T.P. (Org.) (1999). Aconselhamento psicológico centrado na pessoa: novos desafios. São Paulo: Casa do Psicólogo.

Plano de Atendimento à Saúde. Manual do usuário. São Paulo: Prefeitura de São Paulo/ Secretaria Municipal de Saúde, s/d.

Programa de Governo 1999-2002: metas, projetos e programas de impacto social. São Paulo: Governo Mário Covas, s/d.

Instituto Nacional de Assistência Médica da Previdência Social. Programa de Reorientação da Assistência Psiquiátrica. Brasília: MPAS/ CCS, 1983.

Romano, R. (2000). A universidade, o possível futuro e um certo passado. Revista ADUSP, 19, 84-87.

Santos, B.S. (1999). Da idéia de universidade à universidade de idéias. In Pela mão de Alice: o social e o político na pós-modernidade. 5.ed São Paulo: Cortez.

Seligmann-Silva, E. (1999). Desemprego: a dimensão psicossocial. La psicologia al fin del siglo: conferencias magistrales del XXVII Congresso Interamericano de Psicología (v.1) Caracas: Sociedad Interamericana de Psicología.

Silva Jr., J.R., \& Sguissardi, V. (1999). Novas faces da educação superior no Brasil: reformas do Estado e mudanças na produção. Bragança Paulista: EDUSF.

Recebido para publicação em 28 de agosto de 2003 e aceito em 12 de novembro de 2004 